\title{
Hepatic steatosis in a school population of overweight and obese adolescents
}

\author{
Ana R. F. Lira, ${ }^{1}$ Fernanda L. C. Oliveira, ${ }^{2}$ Maria A. M. S. Escrivão, ${ }^{2}$ \\ Fernando A. B. Colugnati, ${ }^{3}$ José A. A. C. Taddei ${ }^{4}$
}

\begin{abstract}
Objective: To assess hepatic steatosis by ultrasound method as a concomitant risk factor among overweight adolescents.

Methods: A case-control study including 83 cases (47 overweight and 36 obese) and 89 controls (normal weight), frequency matched by gender, year of birth, pubertal stage (Tanner 4/5), and income. Cases and controls were selected from 1,420 students enrolled in a Vila Mariana public high school, in São Paulo, Brazil. Must et al. criteria were used for nutritional status classification. Nonalcoholic fatty liver disease was diagnosed through hepatic ultrasonography performed and analyzed by one radiologist. Hepatic enzymatic activities (alanine and aspartate transaminases, alkaline phosphatase, gamma-glutamyl transpeptidase) and direct bilirubin were measured. Eight covariables were fitted into logistic regression models; criterion for inclusion of variables was the association with overweight in the bivariate analyses $(p<0.20)$. A value of $p<0.05$ was set as the criterion for inclusion into the final logistic regression models.

Results: Prevalence of hepatic steatosis diagnosed through ultrasonography was $27.7 \%$ in overweight/obese students and $3.4 \%$ in normal weight students. Adjusted odds ratios (95\% CI) for images compatible with nonalcoholic fatty liver disease and gamma-glutamyl transpeptidase $>24 \mathrm{U} / \mathrm{L}$ were 10.77 (2.45-47.22) and 4.18 (1.46-11.94), respectively.

Conclusions: This is the first population-based study showing that hepatic steatosis is strongly associated with overweight/obesity among adolescents attending a Brazilian public school. The diagnostic tool used in this investigation is a non-invasive method that might be applied to monitor overweight and obese adolescents and to propose actions for preventing more severe hepatic diseases in adulthood.
\end{abstract}

J Pediatr (Rio J). 2010;86(1):45-52: Adolescent, hepatic steatosis, low income population, metabolic diseases, obesity, overweight.

\section{Introduction}

Obesity in adulthood is a limiting factor for quality of life and longevity. Pediatricians' attention to the consequences of obesity in childhood and adolescence have probably begun due to the significant increase of its prevalence in both developed and developing countries. ${ }^{1}$

Between 1980 and 1994, the proportion of children and adolescents considered obese increased $100 \%$ in the USA. ${ }^{2}$ It is estimated that $15.3 \%$ of American children aged 6-11 years and $15.5 \%$ of adolescents aged $12-19$ years present body mass index (BMI) $\geq 95$ th percentile. Approximately $11 \%$ of American children and adolescents between 6 and 17 years old are obese. High prevalence of obesity has been observed in populations of developing countries ${ }^{1}$ and low socioeconomic level. ${ }^{3}$

A national survey ${ }^{4}$ verified that $32 \%$ of the Brazilian adult population presented some degree of overweight or

1. MSc, Pediatrics, Universidade Federal de São Paulo - Escola Paulista de Medicina (UNIFESP-EPM), São Paulo, SP, Brazil.

2. PhD, Pediatrics, UNIFESP-EPM, São Paulo, SP, Brazil.

3. PhD, Health Sciences, UNIFESP-EPM, São Paulo, SP, Brazil.

4. Associate Professor, Discipline of Nutrology, Department of Pediatrics, UNIFESP-EPM, São Paulo, SP, Brazil.

This study was conducted at Discipline of Nutrology, Department of Pediatrics, Universidade Federal de São Paulo - Escola Paulista de Medicina (UNIFESP-EPM), São Paulo, SP, Brazil.

No conflicts of interest declared concerning the publication of this article.

Suggested citation: Lira AR, Oliveira FL, Escrivão MA, Colugnati FA, Taddei JA. Hepatic steatosis in a school population of overweight and obese adolescents. J Pediatr (Rio J). 2009;85(6):45-52.

Manuscript submitted Sep 16 2009, accepted for publication Dec 072009

doi:10.2223/JPED.1969 
obesity. This survey also showed incidences of $10.4 \%$ for overweight and $1.8 \%$ for obesity in adolescents aged $10-19$ years according to the Cole et al. criterion. ${ }^{5}$ Considering the Must et al. criterion the prevalence of overweight (BMI > 85th) was $17.9 \% .^{5}$

Obese children and adolescents present higher probabilities of becoming obese adults with a greater risk of developing cardiovascular diseases, diabetes and some types of neoplasia than normal weight children and adolescents. ${ }^{6}$ Obese children and adolescents also present higher frequencies of dyslipidemia, diabetes, hypertension, orthopedic and postural disorders, dermatitis and respiratory disfunction. ${ }^{7}$

Nonalcoholic fatty liver disease (NAFLD) could be defined as alterations of the hepatic function and damage to hepatic tissues similar to those observed in alcoholic liver disease. ${ }^{8}$ Childhood obesity prevalence has increased and NAFLD has been considered as a relevant disease in children. ${ }^{9}$ The high prevalence of NAFLD in children was recognized only in the past 5 to 10 years, as rates of childhood obesity rose. ${ }^{10}$ NAFLD includes a broad spectrum of liver tissue alterations, ranging from pure hepatic steatosis (HS) without inflammation to nonalcoholic steatohepatitis (NASH) with inflammation and fibrosis, and cirrhosis. ${ }^{8,9}$

Studies of the asymptomatic liver involvement in obese pediatric patients showed greater frequencies of HS and steatohepatitis that had already been reported in the literature of adult obese populations. ${ }^{11}$

NAFLD affects 10 to $24 \%$ of the general population in several countries. NAFLD ranges from simple steatosis, which is the least rapidly progressing disorder to NASH and to cirrhosis that can evolve to chronic liver failure. ${ }^{10}$ The early detection and control of hepatic alterations is important because their progression could raise mortality rates due to cirrhosis among young adults. Two such cases have been reported in obese children, one in a 10-year-old with BMI of $32 \mathrm{~kg} / \mathrm{m}^{2}$ and another in a 14-year-old, BMI of $37.9 \mathrm{~kg} / \mathrm{m}^{2}$, with NASH that progressed to cirrhosis with symptoms of portal hypertension in 2 years. ${ }^{12}$ Disease mechanisms in those cases involved hyperinsulinemia and hepatic insulin resistance, which were not related to ethanol consumption. ${ }^{10}$

HS seems to be caused by the availability and mobilization of free fatty acids (FFA), by increased hepatic FFA synthesis, esterification of FFA into triglycerides and decrease of triglyceride transportation within the liver. According to the standing theory, there would be a deviation of lipolysis in favor of lipogenesis. ${ }^{13}$ The circulating FFA would develop peripheral insulin resistance that could evolve to systemic resistance. HS is currently considered one of the aspects associated with insulin resistance, along with type II diabetes mellitus, visceral obesity, dyslipidemia and hypertension. ${ }^{14}$
The relevant diagnosis of NASH requires a liver biopsy, since some individuals have inflammation and fibrosis despite having normal serum ALT. ${ }^{9}$

The noninvasive ultrasound method was adopted due to better sensitivity ( $89 \%$ ) and specificity (93\%) for the detection of $\mathrm{HS}^{15}$ when compared to the gold standard hepatic biopsy.

The objective of the present study was to evaluate HS by ultrasound method as a concomitant risk factor of overweight and obesity within a low income adolescent population attending a Brazilian public high school.

\section{Materials and methods}

The case-control study was carried out in the city of São Paulo, State of São Paulo, Southeast Brazil, from June through December 2002.

For the selection of cases and controls, a team of trained nutritionists and pediatricians weighed and measured 1,420 adolescents born between 01/01/1983 and 12/31/1988, accounting for $98.68 \%$ of all students enrolled in a public high school of São Paulo. Sixteen youngsters refused to be evaluated, and three were not found after at least three attempts.

From the screened adolescents, 104 were classified as overweight and obese with BMI $\geq 89$ th and adolescents were considered obese when BMI $>$ 95th according to the Must et al. criterion. ${ }^{16}$ Controls (114) were frequency matched by age, gender and pubertal development, and income, and were randomly selected from subjects presenting BMI between 5 th and 85 th percentiles. ${ }^{16}$

The adolescents were measured by trained nutritionists during their physical education classes and, when eligible to participate, were invited to come to school with their parents on a Saturday morning to be informed on the research objectives and to obtain the parents' signature on the informed consent form. Of the 218 (104 cases and 114 controls) eligible adolescents, $19.4 \%$ (17 cases and 25 controls) refused to participate and two subjects (one case and one control) were excluded due to hypothyroidism diagnosed after medical examination and assessment of thyroid hormones levels. Adolescents using drugs that compromise hepatic functions were excluded. Other risk factors such as viral hepatitis and inborn errors of metabolism were not considered. The final sample study comprised 172 adolescents: 47 overweight, 36 obese as cases and 89 normal weight as controls.

A standardized and pretested questionnaire was applied by trained nutritionists and pediatricians to both cases and controls. The following variables were considered: frequency and duration of physical activity (habit of napping, walking less than 1 hour per day, hours of television watching, videogames and computer playing per day); eating habits 
analyzed by total fat intake, eating restriction, use of drugs for weight loss reasons; alcohol intake (consumption of alcohol equal to or higher than three times a week), and relationships (having a best friend; a boy/girl friend). Questions regarding the use of alcohol were made to the adolescents in private without the presence of parents in order to avoid any embarrassment.

In addition to the interview with the adolescent, parents or guardians were also interviewed. At the time, data were collected concerning the adolescent (birth weight, past obesity) and the biological parents (weight and height, measured by trained nutritionists). Parents were considered obese when presenting BMI $>30 \mathrm{~kg} / \mathrm{m}^{2}$.

One of the graduate students involved in the project measured the participants' blood pressure according to the procedures recommended for field work. ${ }^{17}$ High systolic or diastolic blood pressure was defined as a value that exceeded the 95th percentile for age and gender. ${ }^{17}$

The adolescents were referred to the Outpatient Clinic to undergo hepatic ultrasonography and laboratory tests. The hepatic ultrasounds were performed and interpreted by one trained radiologist from the staff of the Department of Imaging Diagnosis, Pediatric Radiology Sector, Universidade Federal de São Paulo (UNIFESP), São Paulo. The equipment used was the LOGIQ 400 PRO-GE model. Liver steatosis was graded as mild, moderate and severe, according to Saverymuttu et al. ${ }^{15}$

The laboratory tests were performed at the UNIFESP Psychobiology Laboratory. Blood samples were collected by peripheral venous puncture in the morning, after 12 to 14-hour fasting. All patients were tested for serum concentrations of alanine (ALT) and aspartate (AST) transaminases, gamma-glutamyl transpeptidase (GGT), alkaline phosphatase, cholesterol, and triglycerides were tested, as well as fasting plasma glucose, fasting plasma insulin concentrations, and glycosylated hemoglobin. The reference value adopted for AST was $37 \mathrm{U} / \mathrm{L}, 30 \mathrm{U} / \mathrm{L}$ for $\mathrm{ALT}$, $24 \mathrm{U} / \mathrm{L}$ for GGT (75th percentile of the total sample), 126 $\mathrm{U} / \mathrm{L}$ for the alkaline phosphatase and $0.30 \mathrm{mg} / \mathrm{dL}$ for direct bilirubin. All adolescents included in this study presented AST/ALT ratio lower than 1 , which indicates that they do not have alcoholic-related liver disease.

The degree of insulin resistance was determined by the homeostatic model assessment-insulin resistance (HOMA) calculating the product of the fasting plasma insulin concentration (in microunits per milliliters) and the fasting plasma glucose concentration (in millimoles per liter) divided by $22.5 .18,19$ Risk of insulin resistance was defined for values greater than 2 (HOMA > 2). ${ }^{19}$

\section{Statistical analysis}

Data were codified by the interviewers daily, and revised by the field study coordinator. The database was structured using Epi-Info 6.0 software and double entered for correction of possible entry mistakes. Analyses were performed using Stata software.

Sample size allowed for detection of an odds ratio (OR) of 3.00, given a prevalence of family obesity among controls of $25 \%$. Assuming $80 \%$ power and $5 \%$ alpha error, the result was 65 cases and 65 controls. This was increased by $10 \%$ possible losses and $10 \%$ stratified analysis leading to a total sample of 78 cases and 78 controls.

Continuous variables were presented as means and standard deviations and for comparisons between obese/ overweight and normal weight adolescents. The Student's $t$ test was adopted to compare means between the groups (Table 1).

Initially, the univariate analysis of all information collected was carried out calculating the proportions for the dichotomous variables. As the next step, bivariate analyses were performed, observing exposure prevalence for cases and controls, association test (Pearson's chi-squared test) and OR with their respective confidence intervals (95\%CI). Finally, the multivariate analysis was carried out - a conditional logistic hierarchical regression model. In each hierarchical level the variables associated to overweight with $p<0.20$ were maintained for their status of possible confounders. In the final models only univariables with $\mathrm{p}<0.05$ were kept.

\section{Ethical considerations}

The present study was approved by the Ethics Committee of UNIFESP, according to the Declaration of Helsinki, World Medical Association. Adolescents presenting ultrasonography or biochemical hepatic enzymes suggestive of HS were referred to the Pediatric Hepatology Unit of our university.

\section{Results}

The prevalence of obesity (BMI $\geq 95$ th) and overweight (BMI between 85th and 95th) in the universe of 1,420 students from which cases and controls were selected, was 4.4 and $10.8 \%$, respectively.

Table 1 depicts the descriptive variables of adolescents and their parents for cases and controls, including the Tanner classification for puberal stage and biochemical profiles. Prevalence of risk factors for cases and controls, as well as the crude and adjusted OR are shown in Table 2.

As for the hepatic ultrasonography, it was verified that the chances of presenting HS in any degree was 10.99 times greater among the cases than in the controls. In this study, $23(27.7 \%)$ overweight/obese adolescents presented some degree of steatosis ( 21 mild and two moderate) whereas only three adolescents with mild HS (3.4\%) were found in the control group. 
Table 1 - Descriptive statistics for cases and controls

\begin{tabular}{|c|c|c|c|}
\hline Variables & Cases $(n=83)$ & Control $(n=89)$ & p* \\
\hline Age (years) & $16.0 \pm 1.0$ & $15.9 \pm 0.9$ & 0.63 \\
\hline Male, $\mathrm{n}(\%)$ & $38(45.8)$ & $43(48.3)$ & 0.74 \\
\hline $\mathrm{BMI}, \mathrm{kg} / \mathrm{m}^{2}$ & $29.7 \pm 2.8$ & $20.2 \pm 1.9$ & 0.00 \\
\hline Tanner's criterion 4 or $5, \%$ & 100 & 100 & \\
\hline Birth weight $(\mathrm{g})$ & $3,215 \pm 628$ & $3,213 \pm 552$ & 0.99 \\
\hline \multicolumn{4}{|l|}{$\mathrm{BP}$} \\
\hline Systolic BP, mmHg & $116 \pm 14$ & $103 \pm 11$ & 0.00 \\
\hline Diastolic $\mathrm{BP}, \mathrm{mmHg}$ & $73 \pm 9$ & $65 \pm 8$ & 0.00 \\
\hline \multicolumn{4}{|l|}{ Lipid profile } \\
\hline $\mathrm{TC} \mathrm{mg} / \mathrm{dL}$ & $167.8 \pm 28.5$ & $159.1 \pm 26.7$ & 0.03 \\
\hline $\mathrm{HDLc} \mathrm{mg} / \mathrm{dL}$ & $45.5 \pm 11.4$ & $51.1 \pm 10.0$ & 0.00 \\
\hline LDLc mg/dL & $102.2 \pm 25.2$ & $93.1 \pm 23.9$ & 0.01 \\
\hline VLDLc mg/dL & $20.1 \pm 1.0$ & $14.8 \pm 4.4$ & 0.00 \\
\hline Triglycerides $\mathrm{mg} / \mathrm{dL}$ & $100.3 \pm 49.9$ & $74.0 \pm 22.0$ & 0.00 \\
\hline \multicolumn{4}{|l|}{ Ultrasonography } \\
\hline Hepatic steatosis (mild/moderate) & $21(2)$ & $3(0)$ & \\
\hline \multicolumn{4}{|l|}{ Hepatic function } \\
\hline GGT U/L & $27.0 \pm 20.8$ & $19.6 \pm 5.5$ & 0.00 \\
\hline ALT U/L & $34.3 \pm 14.0$ & $29.5 \pm 10.8$ & 0.01 \\
\hline AST U/L & $24.4 \pm 7.6$ & $25.4 \pm 13.7$ & 0.58 \\
\hline Alkaline phosphatase $\mathrm{U} / \mathrm{L}$ & $102.9 \pm 43.0$ & $101.4 \pm 51.6$ & 0.84 \\
\hline Direct bilirubin mg/dL & $0.2 \pm 0.1$ & $0.2 \pm 0.1$ & 0.21 \\
\hline \multicolumn{4}{|l|}{$\mathrm{CHO}$ metabolism } \\
\hline HOMA & $2.8 \pm 1.7$ & $1.6 \pm 0.8$ & 0.00 \\
\hline FB insulin concentration $\mu \mathrm{U} / \mathrm{L}$ & $13.7 \pm 0.5$ & $1.8 \pm 0.4$ & 0.00 \\
\hline FB glucose concentration $\mathrm{mg} / \mathrm{dL}$ & $84.1 \pm 6.4$ & $82.9 \pm 6.0$ & 0.00 \\
\hline
\end{tabular}

$\mathrm{ALT}=$ alanine transaminase $\mathrm{AST}=$ aspartate transaminase $; \mathrm{BMI}=$ body mass index $; \mathrm{BP}=$ blood pressure $; \mathrm{CHO}=$ carbohydrates; $\mathrm{FB}=$ fasting blood $; \mathrm{GGT}=$ gammaglutamytranspeptidase; HDLC = high-density lipoprotein cholesterol; HOMA = homeostatic model assessment; $\mathrm{LDLC}=$ low-density lipoprotein cholesterol; $\mathrm{TC}=$ total cholesterol; TG = triglycerides; VLDLc = very low density lipoprotein cholesterol.

* Student's $t$ test.

Results shown in mean \pm standard deviation.

As far as the hepatic enzymes are concerned, it was observed that the chances of presenting GGT above 24 $\mathrm{U} / \mathrm{L}$ were 3.70 times greater in cases than in controls. Only two adolescents had GGT higher than the normal values (78 U/L). Chances for ALT above $30 \mathrm{U} / \mathrm{L}$ were 2.46 times greater in the cases than in the controls. As additional information, not included in the tables, when elevated ALT and presence of steatosis were considred together, there were 12 adolescents in the case group with both abnormalities, whereas in the control group no subject had the two alterations. The chances of presenting increased AST and alkaline phosphatase were 1.79 and 1.01 times greater in cases than in controls, respectively, but with no statistical significance.

The hierarchical conditional logistic regression for overweight, considering HS indicators as concomitant risks is depicted in Table 3.

The adjusted OR shown in the multivariate analyses for parents' history, past obesity and relationships/behavior considered in model 1 were all strongly associated to overweight adolescence, and are discussed in greater detail elsewhere. ${ }^{20}$ The variables of restrictive diets for weight loss, habit of napping, presence of HS in the ultrasonography, GGT and ALT were considered in model 2. Restrictive diets and habit of napping, presence of $\mathrm{HS}$, increased GGT and ALT maintained the statistical significance. The overweight/obesity group had 10.77 times greater chances of presenting ultrasonography HS than the normal weight adolescents. The chances for alterations of GGT in the multivariate analyses were 4.18 times higher among cases when compared with controls.

\section{Discussion}

The prevalence of overweight/obesity found in this study $(15.2 \%)$ is in accordance with the findings of other Brazilian epidemiological studies of low-income populations. ${ }^{20}$ Certain ethnicities are predisposed to NAFLD such as the Hispanic, mainly non-Cuban, Asian, specifically from China and the Philippines, and indigenous people of North and South America. ${ }^{9}$ Ethnic miscegenation constitutes an important characteristic of the Brazilian population, one that does not allow for commitments with specific ethnic groups. 
Table 2 - Prevalences of risk factors for cases and controls, OR with respective confidence intervals

\begin{tabular}{|c|c|c|c|c|}
\hline Risk factors & Cases, \% & Controls, \% & $\begin{array}{l}\text { Crude OR } \\
(95 \% \mathrm{CI})\end{array}$ & $\mathbf{p}$ \\
\hline \multicolumn{5}{|l|}{ Parents' history } \\
\hline Parents' BMI $\left(\geq 30 \mathrm{~kg} / \mathrm{m}^{2}\right)$ & 51.8 & 34.5 & $2.04(1.05-4.00)$ & $0.022 *$ \\
\hline \multicolumn{5}{|l|}{ Past obesity } \\
\hline Infant & 29.3 & 10.2 & $3.63(1.46-9.24)$ & $0.002 *$ \\
\hline Pre-school period & 29.3 & 2.3 & $17.79(3.80-114.97)$ & $0.000 *$ \\
\hline School age & 43.9 & 10.2 & $6.87(2.84-17.08)$ & $0.000 *$ \\
\hline Adolescence & 36.6 & 6.8 & $7.88(2.85-23.00)$ & $0.000 *$ \\
\hline All periods & 18.1 & 1.1 & $19.41(2.55-10.49)$ & $0.000 *$ \\
\hline \multicolumn{5}{|l|}{ Relationships/behavior } \\
\hline Having a best friend & 94.0 & 74.2 & $5.44(1.81-17.53)$ & $0.087 *$ \\
\hline Having a boy/girlfriend & 18.1 & 29.2 & $0.53(0.24-1.16)$ & $0.000 *$ \\
\hline \multicolumn{5}{|l|}{ Treatment of obesity } \\
\hline Eating restriction & 48.2 & 13.1 & $6.17(2.69-14.45)$ & $0.000 *$ \\
\hline Use of drugs for weight loss reasons & 9.8 & 1.2 & $8.65(1.04-191.99)$ & $0.018^{*}$ \\
\hline \multicolumn{5}{|l|}{ Health habits } \\
\hline Alcohol intake $\geq 3$ times/week & 7.2 & 21.3 & $0.29(0.10-0.83)$ & $0.009 *$ \\
\hline Total fat intake $>30 \%$ of total calorie intake & 49.4 & 61.4 & $0.61(0.31-1.21)$ & 0.124 \\
\hline \multicolumn{5}{|l|}{ Physical activity } \\
\hline Physical activity $<3$ times/week and $<30$ minutes & 77.1 & 71.9 & $1.32(0.62-2.80)$ & 0.434 \\
\hline Hours of TV/video/computer watching $\geq 4 \mathrm{~h} /$ day & 19.3 & 18.0 & $1.09(0.47-2.53)$ & 0.827 \\
\hline Habit of napping & 28.9 & 16.9 & $2.01(0.91-4.48)$ & $0.059 *$ \\
\hline Walking $<1 \mathrm{~h} /$ day & 41.0 & 40.4 & $1.02(0.53-1.98)$ & 0.945 \\
\hline \multicolumn{5}{|l|}{ Metabolic repercussions } \\
\hline Resistance to insulin (HOMA > 2) & 68.3 & 23.9 & $6.87(3.30-14.46)$ & $0.000 *$ \\
\hline Dyslipidemia & 38.6 & 9.0 & $6.35(2.53-16.47)$ & $0.011 *$ \\
\hline Hypertension & 14.5 & 2.2 & $7.35(1.47-49.94)$ & $0.011 *$ \\
\hline \multicolumn{5}{|l|}{ Ultrasonography } \\
\hline Hepatic steatosis (mild and moderate) & 27.7 & 3.4 & $10.99(2.92-48.84)$ & $0.000 *$ \\
\hline \multicolumn{5}{|l|}{ Laboratory exams } \\
\hline GGT > $24 \mathrm{U} / \mathrm{L}$ & 36.6 & 13.5 & $3.70(1.63-8.54)$ & $0.000 *$ \\
\hline AST > $37 \mathrm{U} / \mathrm{L}$ & 9.6 & 5.6 & $1.79(0.50-6.71)$ & 0.318 \\
\hline $\mathrm{ALT}>30 \mathrm{U} / \mathrm{L}$ & $53.0+$ & $31.5 \neq$ & $2.46(1.25-4.84)$ & $0.004 *$ \\
\hline Alkaline phosphatase $>126 \mathrm{U} / \mathrm{L}$ & 19.3 & 19.1 & $1.01(0.44-2.32)$ & 0.976 \\
\hline Direct bilirubin $>0.30 \mathrm{mg} / \mathrm{dL}$ & 16.9 & 23.9 & $0.65(0.28-1.48)$ & 0.257 \\
\hline $\mathrm{HDLc}<35 \mathrm{mg} / \mathrm{dL}$ & 19.3 & 3.4 & $6.85(1.75-31.29)$ & $0.000 *$ \\
\hline $\mathrm{LDLC}>130 \mathrm{mg} / \mathrm{dL}$ & 12.0 & 5.6 & $2.30(0.67-8.24)$ & 0.135 \\
\hline Total cholesterol > $200 \mathrm{mg} / \mathrm{dL}$ & 15.7 & 5.6 & $3.12(0.96-10.71)$ & $0.031 *$ \\
\hline Triglycerides > $150 \mathrm{mg} / \mathrm{dL}$ & 14.5 & 1.1 & $14.87(1.91-318.82)$ & $0.000 *$ \\
\hline
\end{tabular}

$95 \% \mathrm{Cl}=95 \%$ confidence interval; ALT = alanine transaminase; AST = aspartate transaminase; BMI = body mass index; GGT = gamma-glutamyl transpeptidase; HDLC = high-density lipoprotein cholesterol; HOMA = homeostatic model assessment; LDLc = low-density lipoprotein cholesterol; OR = odds ratio.

* Significant $p$ values.

$+30 \% \mathrm{ALT}<40 \mathrm{U} / \mathrm{L}$ and $23 \% \mathrm{ALT} \geq 40 \mathrm{U} / \mathrm{L}$.

$\ddagger 20.3 \%$ ALT $<40 \mathrm{U} / \mathrm{L}$ and $11.2 \%$ ALT $\geq 40 \mathrm{U} / \mathrm{L}$.

$\mathrm{p}=$ chi square test.

The risk factors identified in Model 1, which are parents' obesity, infants' obesity, having a best friend, eating restriction and habit of napping are thoroughly discussed elsewhere. ${ }^{21}$

Case and control had significant difference in incidences of metabolic disorder parameters that showed that clinical metabolic repercussions were associated with the increase of body fat mass. Metabolic disorders may develop progressively in the course of life; obesity frequently coming first followed by hyperlipidemia and diabetes. The literature reports evidence that obesity causes secondary hyperlipidemia, ${ }^{8}$ hypertriglyceridemia increasing by five to six times the risk of NAFLD. Acquired obesity seems to lead to fatty liver. ${ }^{22}$ Increased concentration of FFA in the plasma or hepatocytes should be a crucial factor in the development of HS and inflammation. ${ }^{23,24}$ The initial insult would be the development of macrovesicular steatosis with the accumulation of hepatic fat from decreased hepatic free fatty acid oxidation and/or increased hepatic lipogenesis, and/or decreased lipid export from the liver. ${ }^{8}$ As shown in 
Table 3 - Hierarchical conditional logistic regression for overweight, considering hepatic steatosis indicators as concomitant risk factors among public high school adolescents (São Paulo, Brazil)

\begin{tabular}{|c|c|c|c|}
\hline Variables (yes = risk) & Adjusted OR (95\%CI) & $\mathbf{p}$ & Model \\
\hline \multicolumn{4}{|l|}{ Parents' history } \\
\hline Parents' BMI $\geq 30 \mathrm{~kg} / \mathrm{m}^{2}$ & $2.57(1.09-6.04)$ & $0.018 *$ & 1 \\
\hline \multicolumn{4}{|l|}{ Past obesity } \\
\hline Infant period & $4.24(1.41-12.67)$ & $0.005^{*}$ & 1 \\
\hline \multicolumn{4}{|l|}{ Relationship/behavior } \\
\hline Having a best friend & $9.20(2.16-39.07)$ & $0.003 *$ & 1 \\
\hline \multicolumn{4}{|l|}{ Treatment of obesity } \\
\hline Eating restriction & $7.57(2.78-20.57)$ & $0.000 *$ & 1 \\
\hline \multicolumn{4}{|l|}{ Sedentary lifestyle } \\
\hline Habit of napping & $2.99(1.04-8.60)$ & $0.012 *$ & 1 \\
\hline \multicolumn{4}{|l|}{ Ultrasonography } \\
\hline Hepatic steatosis & $10.77(2.45-47.22)$ & $0.002 *$ & 2 \\
\hline \multicolumn{4}{|l|}{ Laboratory exams } \\
\hline GGT > 24 U/L & $4.18(1.46-11.94)$ & $0.007 *$ & 2 \\
\hline $\mathrm{ALT}>30 \mathrm{U} / \mathrm{L}$ & $1.38(0.53-3.54)$ & $0.500 *$ & 2 \\
\hline
\end{tabular}

$95 \% \mathrm{Cl}=95 \%$ confidence interval; $\mathrm{ALT}=$ alanine transaminase AST = aspartate transaminase; $\mathrm{BMI}=$ body mass index; GGT = gamma-glutamyl transpeptidase * Significant $p$ values.

Model 1 = parents' BMI, infant obesity, having a best friend, alimentary restriction and habit of napping.

Model 2 = hepatic steatosis, GGT > $24 \mathrm{U} / \mathrm{L}$ and ALT > $30 \mathrm{U} / \mathrm{L}$.

$\mathrm{p}=$ chi-square test.

other studies, resistance to insulin is strongly related to risk factors for HS, including obesity and dyslipidemia. 25,26 Resistance to insulin, as measured by the HOMA, had greater prevalence in overweight and obese adolescents. The presence of mild resistance to insulin could be the first stage of NAFLD and it is related to the most advanced stages of NAFLD in the most severe cases (type II diabetes); therefore, it is directly related to the degree of hepatic involvement. ${ }^{27}$ Alterations in the fasting plasma glucose concentration or in glycosylated hemoglobin were not observed in the present study. Disorders of the metabolism of glucose, from alterations of glycemia under fasting to the tolerance to glucose, as well as diabetes, are all significantly associated with HS. Family history of type II diabetes was found to increase the risk of this disease. ${ }^{8}$ The association of excess body fat with diabetes, hypertension and/or altered lipid metabolism has been identified as a distinct entity referred to as metabolic syndrome carrying a high risk of cardiovascular disease. ${ }^{8}$ Authors refer NAFLD and NASH as hepatic expressions of the metabolic syndrome. 28

The hepatic ultrasonography should be the first imaging method to be requested by the physician for overweight children and adolescents, since it is a good method to identify fatty liver. There is a diffuse increase in echogenicity, which is usually described as bright liver. ${ }^{12}$ The prevalence of fatty liver was $15.1 \%(26 / 172)$ among adolescents. In a retrospective review of 742 children and adolescents who had an autopsy performed by a county medical examiner, the prevalence of fatty liver adjusted for age, gender, race, and ethnicity was estimated at 9.6\%. Fatty liver prevalence increases with the age ranging up to $17.3 \%$ for the ages 15 to 19 years, $^{29}$ so this period of life is critical for the development of fatty liver disease. ${ }^{30}$

The hepatic ultrasonography presented a high prevalence of HS in the group of cases. Even after adjustments for the remaining variables analyzed, the multivariate analysis showed that the HS had 10.77 times greater chances of occurring among the cases than in the control group.

A study performed with 72 obese children and adolescents (4-16 years) found that 53\% had fatty liver verified in the sonogram. ${ }^{1}$ Yet, in another study with 36 children (4-16 years) from whom $83 \%$ were obese, 24 (77.4\%) showed abnormalities including hepatomegaly and increased echogenicity suggestive of fatty infiltration. Among obese individuals, HS prevalence varied from 57.5 to $74 \% .31,32$ For child populations such prevalence is estimated to be $2.6 \%,{ }^{33}$ whereas for obese children HS prevalence in different studies varied from 22.5 to $52.8 \% .{ }^{1,30}$ In morbid obesity ${ }^{34}$ an increase of echogenicity was found in $58.8 \%$ of patients with abdominal pain symptomatology and altered the biochemical hepatic enzymatic concentrations. Children who have any stage of NAFLD are usually overweight or obese, although one study has shown NAFLD in approximately $10 \%$ of not overweight children. ${ }^{9}$

Thus, when the present study results are compared with the literature, one observes that the patients included in 
the above mentioned studies were children and adolescents that had been followed by a specialist physician in an obese health care institution. Otherwise, the subjects of this study were selected from adolescents attending a public high school. In terms of external validity, the findings of this study can be safely extrapolated to urban overweight and obese adolescents of low income in other developing population. The fact that high prevalence of mild fatty liver occurs in overweight adolescents shows that overweight increases the risk for development of such a disease, adding to environmental and genetic risk factors that speed up the progression of hepatic injury.

The current literature indicates that in the NAFLD the increase in transaminases is solely represented by ALT rather than by AST; serum AST abnormalities occur exclusively in severe fatty liver cases. 28,35 They also reported that the values of alkaline phosphatase and direct bilirubin tend to be normal in NAFLD. 1,34

The present study was based on a community student population and has shown that there was a significant difference in ALT values between the overweight and the control group; 12 adolescents of the case group had some degree of fatty liver with ALT values higher than $30 \mathrm{U} / \mathrm{L}$, which could be interpreted as evolution from HS to steatohepatitis. Therefore, many children have normal liver tests, notably normal serum aminotransferase and presumed to have simple steatosis. A small proportion of those children might have NASH histologically despite normal liver tests. ${ }^{9}$ In the literature, adolescents had a lot of environmental risk fators such as drugs, medications and infeccious diseases that might alter ALT values, but the increase of body mass have to be considered as an important factor for the development of HS. The literature indicates that the increase of body fat mass will improve the hepatic injury, increasing the degree of HS and evolving to steatohepatitis. ${ }^{14}$ Insulin resistance seems to be the primary factor to result in hepatic fat accumulation, followed by oxidative stress, mitochondrial dysfunction and adipocytokines; the association of these factors promote inflammation and liver disease (necrosis and fibrosis). ${ }^{14,30}$

Among adult population, the diagnosis of HS is often made by means of routine biochemical exams, revealing alterations in transaminases, which occur differently in children and adolescents in whom there is a gradual increase of these enzymes with the progression of the disease. ${ }^{26}$ The present study with adolescents from a Brazilian public school shows that HS had greater association with obesity and in its initial stage had mild transaminases alterations, which could lead to more severe hepatic alterations in the future. 12,30

According to the Third Report of the National Cholesterol Education Expert Panel on Detection, Evaluation and Treatment of High Blood Cholesterol in Adults, one that can be applied to the general population, the metabolic syndrome is present in $60 \%$ of females and in $30 \%$ of males affected by HS. The presence of the metabolic syndrome carries a threefold increase risk of NASH among NAFLD subjects. The metabolic syndrome is particularly associated with high risk of fibrosis or cirrhosis, without differences in the degree of HS and of necroinflammatory activity enzymes. ${ }^{8}$

The present study showed a strong association between obesity and HS among Brazilian adolescents from a public high school. Therefore, adolescents of low-income families, who are overweight, obese and asymptomatic constitute a risk group for the development of hepatic repercussions, in addition to metabolic alterations. This suggests that adolescents from low-income urban populations should be targeted for prevention policies and programs to identify risks of HS and their health consequences.

\section{Acknowledgements}

The authors would like to thank Fundação de Amparo à Pesquisa de São Paulo - FAPESP for the financial support, grant 03/00415-4.

\section{References}

1. Franzese A, Vajro P, Argenziano A, Puzziello A, Iannucci MP, Saviano $M C$, et al. Liver involvement in obese children. Ultrasonography and liver enzyme levels at diagnosis and during follow-up in an Italian population. Dig Dis Sci. 1997;42:1428-32.

2. National Center for Health Statistics. Center for Disease Control and Prevention. [website] Health E-Statis, 2001. Prevalence of overweight among children and adolescents. United States; 1999. http://www.cdc.gov/nchs/releases/01news/overweight99.htm Access: 04/09/2003.

3. Mei Z, Scanlon KS, Grummer-Strawn LM, Freedman DS, Yip R, Trowbridge FL. Increasing prevalence of overweight among US low-income preschool children: the Centers for Disease Control and Prevention pediatric nutrition surveillance, 1983 to 1995. Pediatrics. 1998;101:E12.

4. Coitinho DC, Leão MM, Recine E, Sichieri R. Condições nutricionais da população brasileira: adultos e idosos: Pesquisa Nacional sobre Saúde e Nutrição. Brasília: Instituto Nacional de Alimentação e Nutrição; 1991.

5. Instituto Brasileiro de Geografia e Estatística. Pesquisa de orçamentos familiares 2002-2003: antropometria e análise do estado nutricional de crianças e adolescentes no Brasil. Rio de Janeiro: IBGE; 2006.

6. Freedman DS, Dietz WH, Srinivasan SR, Berenson GS. The relation of overweight to cardiovascular risk factors among children and adolescents: the Bogalusa Heart Study. Pediatrics. 1999; 103:1175-82.

7. World Health Organization. Preventing and managing the global epidemic. Report of a WHO Consultation on Obesity. Geneva: WHO; 1997.

8. Festi D, Colecchia A, Sacco T, Bondi M, Roda E, Marchesini G. Hepatic steatosis in obese patients: clinical aspects and prognostic significance. Obes Rev. 2004;5:27-42.

9. Roberts EA. Non-alcoholic steatohepatitis in children. Clin Liver Dis. 2007; 11:155-172, $\mathrm{x}$.

10. Roberts EA, Yap J. Nonalcoholic Fatty Liver Disease (NAFLD): approach in the adolescent patient. Curr Treat Options Gastroenterol. 2006;9:423-31. 
11. Bacon BR, Farahvash MJ, Janney CG, Neuschwander-Tetri BA. Nonalcoholic steatohepatitis: an expanded clinical entity. Gastroenterology. 1994;107:1103-9.

12. Molleston JP, White F, Teckman J, Fitzgerald JF. Obese children with steatohepatitis can develop cirrhosis in childhood. Am J Gastroenterol. 2002;97:2460-2.

13. Okolo P, Diehl AM. Nonalcoholic steatohepatitis and focal fatty liver. In: Feldman M, Sleisenger MH, Scharschmidt BF, editors. Sleisenger \& Fordtran's gastrointestinal and liver diseases. Philadelphia: WB Saunders; 1998. p. 1215-20.

14. McCullough AJ. Update on nonalcoholic fatty liver disease. J Clin Gastroenterol. 2002;34:255-62.

15. Saverymuttu SH, Joseph AE, Maxwell JD. Ultrasound scanning in the detection of hepatic fibrosis and steatosis. British Medical Journal. 1986;292:13-5.

16. Must A, Dallal GE, Dietz WH. Reference data for obesity: 85th and 95th percentiles of body mass index (wt/ht2) and triceps skinfold thickness. Am J Clin Nutr. 1991;53:839-46. Erratum in: Am J Clin Nutr. 1991;54:773.

17. National High Blood Pressure Education Program Working Group on Hypertension Control in Children and Adolescents. Update on the 1987 task force report on high blood pressure in children and adolescents. Pediatrics. 1996;98:649-58.

18. Weiss R, Dziura J, Burgert TS, Tamborlane WV, Taksali SE, Yeckel $\mathrm{CW}$, et al. Obesity and the metabolic syndrome in children and adolescents. N Engl J Med. 2004;350:2362-74.

19. Barja S, Arteaga A, Acosta AM, Hodgson MI. Insulin resistance and other expressions of metabolic syndrome in obese Chilean children. Rev Med Chil. 2003;131:259-68. Erratum in: Rev Med Chil. 2003;131:577.

20. Giuliano IC, Coutinho AS, Freitas SF, Pires MM, Zunino SN, Ribeiro RQ. Lípides séricos em crianças e adolescentes de Florianópolis, SC: Estudo Floripa Saudável 2040. Arq Bras Cardiol. 2005;85:85-91.

21. Silveira D, Taddei JA, Escrivão MA, Oliveira FL, AnconaLopez F. Risk factors for overweight among Brazilian adolescents of low-income families: a case-control study. Public Health Nutr. 2006;9:421-8.

22. Pietiläinen $\mathrm{KH}$, Rissanen $\mathrm{A}$, Kaprio J, Mäkimattila $\mathrm{S}$, Häkkinen AM, Westerbacka J, et al. Acquired obesity is associated with increased liver fat, intra-abdominal fat, and insulin resistence in young adult monozygotic twins. Am J Physiol Endocrinol Metab. 2005;288:E768-74.

23. de Almeida IT, Cortez-Pinto $H$, Fidalgo $G$, Rodrigues $D$, Camilo ME. Plasma total and free fatty acids compsition in human nonalcoholic steatohepatitis. Clin Nutr. 2002;21:219-23.

24. Boden $G$, She $P$, Mozzoli $M$, Cheung $P$, Gumireddy $K$, Reddy $P$, et al. Free fatty acids produce insulin resistance and activate the proinflammatory nuclear factor-kappaB pathway in rat liver. Diabetes. 2005;54:3458-65.
25. Westerbacka J, Lammi K, Häkkinen AM, Rissanen A, Salminen I, Aro $A$, et al. Dietary fat content modifies liver fat in overweight nondiabetic subjects. J Clin Endocrinol Metab. 2005;90:2804-9.

26. Birkner E, Kasperczyk S, Kasperczyk A, Zalejska-Fiolka J, ZwirskaKorczala K, Stawiarska-Pieta B, et al. Metabolic and antioxidative changes in liver steatosis induced by high-fat, low-carbohydrate diet in rabbits. J Physiol Pharmacol. 2005;56:45-58.

27. Marchesini G, Brizi M, Morselli-Labate AM, Bianchi G, Bugianesi E, McCullough AJ, et al. Association of nonalcoholic fatty liver disease with insulin resistance. Am J Med. 1999;107:450-5.

28. Manton DN, Lipsett J, Moore DJ, Davidson GP, Bourne AJ, Couper RT. Nonalcoholic steatohepatitis in children and adolescents. Med J Aust. 2000;173:476-9.

29. Schwimmer JB, Deutsch R, Kahen T, Lavine JE, Stanley C, Behling C. Prevalence of fatty liver in children and adolescents. Pediatrics. 2006;118:1388-93.

30. Patton HM, Sirlin C, Behling C, Middleton M, Schwimmer JB, Lavine JE. Pediatric nonalcoholic fatty liver disease: a critical appraisal of current data and implications for future research. J Pediatr Gastroenterol Nutr. 2006;43:413-27.

31. Bellentani S, Saccoccio G, Masutti F, Crocè LS, Brandi G, Sasso $F$, et al. Prevalence of and risk factors for hepatic steatosis in Northern Italy. Ann Intern Med. 2000;132:112-7.

32. Luyckx FH, Desaive C, Thiry A, Dewé W, Scheen AJ, Gielen JE, et al. Liver abnormalities in severely obese subjects: effect of drastic weight loss after gastroplasty. Int J Obes Relat Metab Disord. 1998;22:222-6.

33. Tominaga K, Kurata JH, Chen YK, Fujimoto E, Miyagawa S, Abe I, et al. Prevalence of fatty liver in Japanese children and relationship to obesity. An epidemiological ultrasonographic survey. Dig Dis Sci.1995;40:2002-9.

34. Fishbein $\mathrm{MH}$, Miner $M$, Mogren $\mathrm{C}$, Chalekson J. The spectrum of fatty liver in obese children and the relationship of serum aminotransferases to severity of steatosis. J Pediatr Gastroenterol Nutr. 2003;36:54-61.

35. Angulo P, Keach JC, Batts KP, Lindor KD. Independent predictors of liver fibrosis in patients with nonalcoholic steatohepatitis. Hepatology. 1999;30:1356-62.

\section{Correspondence:}

José Augusto de Aguiar Carrazedo Taddei

Disciplina de Nutrologia, Departamento de Pediatria, Universidade Federal de São Paulo

Rua Loefgreen -1647 - Vila Clementino

CEP 04040-032 - São Paulo, SP - Brazil

Tel.: + 55 (11) 5084.4538

Fax: +55 (11) 5084.4538

E-mail: taddei.dped@epm.br, nutsec@yahoo.com.br 